\title{
Research Trends in Rate-Controlled Speech for Language Learning
}

\author{
John Driscoll
}

\begin{abstract}
In research accomplished to date in rate-controlled speech recording relatively few have treated foreign language teaching/learning. This article reviews salient studies and reports on a research study attempted under a Graduate School Research Fund Grant at the University of Washington. Research in the field tends to illustrates both the great potential for rate-control in foreign language teaching and the lack of a theoretical structure for such practice.
\end{abstract}

If we look back over research and analytical writing concerning language laboratories, little doubt is left that some people have been disappointed. Expectations of the early sixties have often slid into apathy, if not rejection of many audio-lingual practices. Although most studies reported have compared traditional language learning with that including laboratory practices, little was asked about the "kind" of laboratory experience. Overall generalizations have often been attempted without differentiating between such kinds (Hocking, 1970). But for all the criticisms of research designs, it has been reasonably demonstrated that there has been a trend established toward better spoken performance when regular laboratory experience has been provided (Chong, 1979). Moreover, as expected, better oral comprehension has been reported in a great many studies.

The trouble has been, of course, that we started out expecting miracles, never allowing for the infamous Hawthrone Effect', and being overly-impressed by certain exponents of the laboratory's uniqueness in language learning. L'oreille electronique was, for instance, reported to produce accent-free French in two short years (Bauer, 1963). For overblown expectations there has often been a certain natural fondness.

A recent embellishment of technologically-aided language learning has been the miniaturization of electronic equipment. This phenomenon has led to two other very interesting facets of such learning. These are the long-needed amelioration of language laboratory logistics, and the student control of recorded speech rate. The highly portable (some smaller than a text book) cassette play-back or recorder-play-back unit has now made feasible language laboratory practice away from the laboratory itself. Obviously, the motivated student can now work at improving his oral comprehension with a great deal more convenience than frequent trips to, and hours at, a language laboratory in a certain building.

The other facet of the miniaturization process has been the recent reduction in size and cost of so-called "speech compressors." Until recently a quite research-oriented piece of equipment, the speech expansion compression module is now both small in size and relatively 
inexpensive. A recent review of such equipment currently on the market treated no less than 16 different devices, ranging in price from $\$ 85.00$ to $\$ 1,000.00$ and available through both American and Japanese electronic manufacturers. ${ }^{2}$ These 16 models were improvements upon some 11 recorders no longer manufactured, but patents for which are still held.

According to Tadashi Koretsune, President of the National Translation Institute of Science and Technology, which is recognized as Japan's official language and translation body, a major hurdle faced by language students is their inability to comprehend a foreign language as it is heard in the real world, outside of the academic situation (1974). The automatic, instantaneous decoding and encoding of a foreign tongue must be undertaken in a major way by the language student and he has to learn in multiple ways how to do so. One learning method has been listening to and recording speech patterns, usually in the formal setting of the language laboratory.

The promise of rate-controlled speech has long loomed over experimentation in language learning and likewise over research therein. Early research in rate-controlled speech was accomplished by some of its first benefactors, the blind, (cf. Duker, (1974), p. 501 and Foulke, (1966), p. 11). But saving time is only one benefit of rate-controlled recordings: analysis of sounds and rhythmic patterns, and intensified practice in recognizing them, are also uses of rate-controlled speech and are two of particular interest to language instruction.

There seems to be a dichotomy between the relatively few studies accomplished to date concerned with rate-controlled recordings in foreign language learnings; namely those preferring expanded (slowed) speech recording and those utilizing compressed (speeded) speech.

\section{Expanded Speech}

It is to be expected that both equipment salesman and some teachers would assume that foreign words are difficult to learn because they are not carefully and slowly analyzed and that some process of slowing down the production of the sound of foreign words and phrases would be of considerable help, particularly to the beginning student. While this assumption might or might not be valid, less interest has been shown in expansion of foreign language learning tapes than in their compression. Back in 1967 at the International Congress of Psychology at Mexico City, David Orr made a case for the use expanded speech in second language learning (Duker, 1974). Since then a modest few but interesting approaches have been made to the problem. Neville and Pugh (1975) found that expanding text material used as a silent reading pacer aided foreign students in English comprehension. Another attempt at using expanded speech has been undertaken by Heilmann (1978) in assessing aural processing capacity of foreign language learners. She hypothesized that expanding French speech $150 \%$ of original time would facilitate oral comprehension and, further that the sex of learners could affect such learning ability. Harvey (1979) has proposed investigating the use of expanded speech in learning Spanish as a second and as a third language. 
Tonal languages require precise tonal differentiation for meaning. Chong (1979) employed expanded recordings in first year Chinese (Mandarin) classes. Although his results implied an advantage for students practicing tonal comprehension with slowed speech, his sample was too small due to the number of students available during the time of the attempted study.

A study employing expanded speech in high school French classes was undertaken by Flaherty (1975) but for testing of oral comprehension rather than for comprehension training. Not unsurprisingly, students hearing expanded French tapes tested significantly better than those hearing normal rate recordings. (She felt an important implication of the study establishing an optimal degree of expansion.)

\section{Compressed Speech}

Hughes (1974) reported two experiments investigating reaction time in identification of compression words. In both studies reaction time increased with increased time compression, suggesting that, due to retroactive inhibition or to response competition, accurate recognition of words comprising continuous speech declines in some ratio to degree of compression. This effect stands beside the assumption that, as accurate word identification declines, comprehension declines.

Russian and French has been featured in several experiments with compressed language tapes. Friedman and Johnson (1971) reported introducing pauses into Russian and Vietnamense sentences and then compressing the sentences to compensate for pause time. They found the compression factor did not interfere with the recall process. Huberman and Medish (1974) also employed compression and purposely inserted pauses in a study involving Russian, German, Spanish, French, Hebrew and Japanese and reported both a reduction of student listening time and improved oral comprehension.

Of the studies done with compressed foreign language tapes, one of the most ambitious was that undertaken by Marion Meyerson in a doctoral dissertation comparing comprehension of compressed speech by native speakers of Japanses, Chinese, Hindi and English. She found that the languages did indeed differ in compressability. Hindi, for example, suffered most, probably due to the dearth of technical terms available, and that Chinese presented intelligibility problems at rate of 50 and $60 \%$ compression but not at $40 \%$ or below. It was assumed this resulted from the limited redundancy in the monosyllabic structure and phonemic tone degradability of the language. Despite prosodic factors, all four languages were intelligible at 0 to $40 \%$ compression.

At the University of Ottawa, Neufeld's very interesting investigation of compressed speech as a measure of comprehension, rather than a comprehension training device, was based on the hypothesis that second language comprehension requires not only linguistic knowledge, but also psycholinguistic skills refined in learning the first language.

Goldhaber's comparative study of the effects of training on native speakers of English, Spanish and Navajo indicated that a two hour training 
period improved oral comprehension, as well as their recall. There were no significant differences between language groups.

Phillips (1979) tried using compressed speech recordings to the end of increasing the reading rate in Spanish to eliminate conscious Spanishto-English translation. Students were asked to use rate-controlled tapes as pacers to force faster reading. Although this fascinating question is still unanswered due to a small population and lack of controls in the study. Phillips results did imply an advantage in reading rate increases for his experimental group.

Because French is not truly phonetic and contains many liaisons which must be learned for instant recognition, the writer hypothesized that students trained at faster than normal classroom speech would be able to increase comprehension more rapidly than students utilizing normal recordings.

Individuals in two first-year French classes were randomly assigned to two groups practicing oral comprehension via cassette play back units. Each student was loaned a playback unit for the quarter and a different cassette each week for home listening. Students were given a written test of oral comprehension ability before and after the use of the cassette. The control group utilized normal-rate recordings. The experimental group was given the same recording compressed at $40 \%$. Their dictations were rated by a French instructor different from their regular teacher. However, the comparison, not unlike graded essay examinations, was a crude one, though results seemed to favor the experimental group slightly.

A second attempt was based on a standardized objective test of oral comprehension (Modern Language Association) allowing more exact measurement of student abilities. Although overall class means on prepost differentials were significantly in favor of the experimental group, comparison of factored groups did not reveal significant difference. Moreover with group N's of less than 20, it soon became obvious that other classes will have to be tested, if results are to be meaningful. Because of logistical problems related to batteries, cassettes, class scheduling changes and failure to procure truly programmed text material for the various cassettes, it is deemed that at least two more quarters of testing will be needed.

There are many problems connected with take-home lab exercises beyond the expected logistical complications. Whereas students express enthusiasm at the quarter's beginning, as other academic matters impinge on their program, it is likely they will find less time for the discipline of daily listening outside class. Unlike certain types of laboratory experience, language lab experience of this type cannot be truly monitored, nor even accurately tallied.

Thus, consistency of practice may not be as factual as professed, particularly outside the threat of grading. How the research design should be modified, if the same standardized test is the best, or even if compressed speech should be a viable part of second-language acquisition are urgent questions to such research. Alteration of speech patterns, never- 
theless, seems a most natural way to increase the instantaneous recognition of them, if fluency is ever to be achieved.

\section{Conclusions}

The problems peculiar to rate-control studies, as well as language practice research in general, have impeded any theoretical structure upon which expanded/compressed speech is to be used in future language instruction. It is reasonable that control of word rate is potentially a valuable tool for the learning process. But how can it best be used? Even the various studies so far accomplished in the area of comprehension do not add up to much more than implication foreign tongues are better understood or after listening to them at an abnormal rate. Though a few of the studies reported here would not measure up to guidelines of rigorous, scientifically-controlled research, some of the ideas are downright fascinating and betray great insight into the language-learning process. The practice, for example, of using increasingly faster compressed speech to impliment increasingly faster reading ability should challenge any language teacher's funny bone. The fact that languages compress differently and to different effect should be more than a bag of worms. Cognitive psychologists have been telling us for a long time we do not truly understand language acquisition.

A Canadian researcher (see Patel 1972) has challenged the psycholinguistic tenant that speech information coming to the listener is grouped (or chunked) according to his/her linguistic knowledge. Patel claims that as research on comprehension of compressed speech suggests that processing time is the important variable in sentence decoding, it follows we might well question evidence that syntactic processing must take place in some sort of "semantic void." This seems a curiously imaginative manner of employing rate-control in probing the immense mystery of language acquisition.

There are other psycholinguistic assumptions which might be questioned by research in rate-control of speech. But there are also long-held traditions and expectations in language teaching which such a line of research might bring to task. What do we really know about the various kinds of listening behavior? Why do we attend to some parts of speech and not others? What is the relationship between anxiety and careful rational listening? What is the relationship between listening behavior and processing abilities, regardless of their derivation? Could we not better understand what students at elementary and intermediate levels miss and why they miss certain parts of sentences. Indeed, the temporal aspects of foreign language speech have only been scratched by the ratecontrol research accomplished to date: the prospects are almost unlimited.

Foulke and Sticht (1969) remind us that "the understanding of spoken language implies the continuous registration, encoding, and storage of speech information, and these operations require time." It is time which rate-control can modify. If we can manipulate the time element in the production/reproduction of speech, perhaps we will be able to manipulate favorably the long and sometimes tedious path to language learning. 


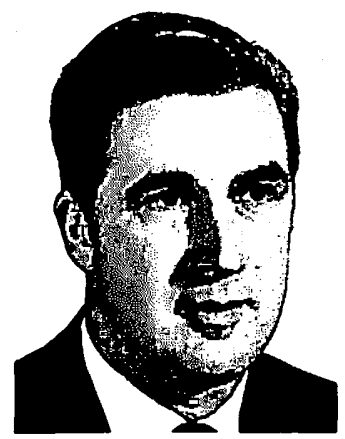

John P. Driscoll

Curriculum and Instruction

University of Washington

Seattle, Washington 98195

\section{NOTES}

1. The effect has been well documented in experimental literature and can be briefly characterized as reporting false results due to the novelty of the experimental situation.

2. "Currently Available," Center for Rate-Controlled Recordings Newsletter, 13:5, September 1979, p. 1.

\section{REFERENCES}

Bauer, Eric, "New Avenues of International Cooperation in Audiovisual Language Teaching," AV Communication Review, 11:200 September October, 1963.

Chong, Lu-sheng, An Examination of the Relationship between Teaching Method in Foreign Language Instruction and the Use of the Language Laboratory, University of Washington (Unpublished doctoral dissertation), 1979, p. 43.

Duker, Sam, Time-compressed speech; an anthology and bibliography in three volumes, Metuchen, N.J.: Scarecrow Press, 1974.

Eddy, F. and Hocking, E., "Language Learning Today - 45 Questions and Answers," Audiovisual Instruction, 4:6 September 1959, p. 197.

Flaherty, E. Sr., The Effect of Time-Expansion on Listening Comprehension of High School Students in Second-Year French Classes. (Unpublished doctoral dissertation), Ohio State University, 1975.

Foulke, E., "The Retention of Information Presented at an Accelerated Word Rate," International Journal for the Education of the Blind, 1966, 16:1, pp. 11-15.

Foulke, E. \& Stickt, T., "Review of Research on the Intelligibility and Comprehension of Accelerated Speech," Psychological Bulletin, 72:1, 1969, p. 50.

Friedman, H. \& Johnson, R., "Rate-Controlled Speech and Second Language Learning," in Proceedings of the Second Louisville Conference on Rate and/or Frequency Controlled Speech, October 22-24, 1969, ed. Emerson Foulke (Louisville: Center for Rate Controlled Recordings, 1971), pp. 323-27.

Goldhaber, G., "Effects of Speech Compression Training on Comprehension of Native Speakers of English, Spanish and Navajo," in Duker. S., op.cit. p. 501. 
Harvey, E., "Is There a Role for Rate-Controlled Recorded Speech in Foreign Language Learning?" Center for Rate-Controlled Recordings Newsletter, 13:3, May 1979, p.1.

Heilmann, L., "The Effect of Rate and Structure on the Processing of Spoken French by Third-Semester College Students," Center for Rate-Controlled Recordings Newsletter, 12:1, January 1978, p. 1.

Hocking Elton, "Technology in Foreign Language Teaching," The Modem Language Journal, 54:2, February 1970, pp. 79-91.

Huberman, G., \& Medish, V., "A Multi-Channel Approach to Language Teaching" Foreign Language Annals, 7(1974), 674-80; "Spanish MultiChannel Instruction in Operation: A Progress Report," Foreign Language Annals, 8(1975), 49-52.

Hughes, L., "Reaction Time in Identifying Compressed Words," Center for Rate-Controlled Recordings Newsletter, 8:2, February 1974, p. 1.

Koretsune, T., in "Variable Speech Control Company Names Japanese Distributor," Center for Rate-Controlled Recordings Newsletter, 12:3, March 1978, p. 3.

Meyerson, M., An Exploration of Compression Differences in TimeCompressed Japanese, Chinese, Hindi and English, (Unpublished doctoral thesis), University of Illinois, 1971.

Neufeld, G., Using Speech Compression as a Means of Assessing Competence in Listening Comprehension, Ottawa: University of Ottawa, Series: AILA, 19780255.

Neville, M. \& Pugh, A. "An Exjloratory Study of the Application of TimeCompressed and Time-Expanded Speech in the Development of the English Reading Proficency of Foreign Students," English Language Teaching Journal, 29:4, July 1975, p. 320.

Patel, P., Perceptual Processing Time \& Semantic Information, Ottawa: University of Ottawa, Folia Linguistira, 1972, 6(1/2). pp. 152-166.

Phillips, Robert, Unpublished report on compressed speech in the teaching of Spanish, Oxford, Ohio: Miami University, October 8, 1979. 